DOI

\title{
НЕОТЛОЖНАЯ ЭНДОВИДЕОХИРУРГИЯ ПРИ ОСТРЫХ ЗАБОЛЕВАНИЯХ ОРГАНОВ БРюшНОЙ ПОЛОСТИ
}

\author{
๑У. Б. Абдуллаев, С. И. Нарзуллаев, К. Р. Тагаев \\ Самаркандский Государственный медицинский институт, \\ Самаркандский филиал Республиканского научного центра экстренной медицинской помощи, \\ Республика Узбекистан
}

РЕЗЮМЕ. В основу исследования вошли результаты диагностики и лечения 1812 больных, которым были выполнены видеоэндоскопические вмешательства по поводу неотложных хирургических заболеваний брюшной полости, а также видеолапароскопия с диагностической целью. В ходе проведенных исследований установлено, что видеолапароскопия является высокоэффективным, безопасным, малотравматичным способом хирургического лечения. Сокращается количество напрасных лапаротомий и их осложнений в виде эвентраций, послеоперационных грыж и нагноений ран.

КЛЮчЕВЫЕ СЛОВА: лапароскопия, эндовидеохирургия, сочетанная травма живота.

Актуальность. Создание национальных $и$ международных журналов, ассоциаций и обществ, огромное количество публикаций в отечественных и зарубежных изданиях, на сайтах Интернета, посвященных вопросам эндоскопической хирургии, лишь подчеркивают важность и актуальность эндохирургии как неотъемлемой составной части хирургии [2].

Широкие диагностические возможности эндовидеохирургии, минимальная травматичность, ранняя реабилитация больных и незначительное количество осложнений делают эндохирургический метод ценным не только для плановой, но и для экстренной хирургии. Широкое применение лапароскопии при основных хирургических заболеваниях и повреждениях органов брюшной полости позволяет в предельно сжатые сроки и с высокой степенью достоверности поставить правильный диагноз, наметить тактику лечебных мероприятий, снизить процент необоснованных лапаротомий $[1,3]$.

Целью исследования явилось изучение эффективности применения эндовидеохирургических операций у больных с экстренной хирургической патологией органов брюшной полости.

Материал и методы исследования. Материалом исследования послужили результаты диагностики и лечения 1812 больных, которым были выполнены эндовидеохирургические вмешательства по поводу неотложных хирургических заболеваний брюшной полости, находившихся на лечении в Самаркандском филиале РНЦЭМП в период с 2010 по 2014 годы. Видеолапароскопия с диагностической целью выполнена 237 пациентам, холецистэктомия выполнена 1012 больным, аппендэктомия - у 178, ушивание перфоративной язвы - 175, рассечение спаек при острой спаечной кишечной непроходимости - 86, при гемоперитонеуме у больных с сочетанной травмой живота и забрюшинного пространства - 63, для диагностики ранних послеоперационных осложнений-61 пациенту.

Результаты и обсуждения. В 57 (24,1\%) наблюдениях использование диагностической видеолапароскопии при закрытой травме живота позволило своевременно выявлять повреждения органов брюшной полости.

Видеолапароскопия позволила избежать выполнения лапаротомии у 39 (16,5 \%) пациентов с подозрением на острый аппендицит. При этом в основном выявлялся мезаденит и пельвиоперитонит. При подтверждении диагноза острого аппендицита во время выполнения диагностической лапароскопии производили видеолапароскопическую аппендэктомию. Противопоказанием к лапароскопической аппендэктомии считали распространенный гнойный перитонит, аппендикулярный инфильтрат, выраженный спаечный конгломерат в области слепой кишки. Лапароскопическая аппендэктомия выполнена у 178 больных с различными формами острого деструктивного аппендицита. Формирование культи червеобразного отростка осуществлялось лигатурным способом. Осложнений в раннем послеоперационном не отмечено. Следует отметить, что в послеоперационном периоде больные после видеолапароскопической аппендэктомии в обезболивающих препаратах нуждались значительно реже, чем после традиционной аппендэктомии.

У пациентов с острым холециститом выполнено 1012 срочных холецистэктомий. При этом в 32 (3,2 \%) случаях произведена конверсия в связи с необходимостью ревизии общего желчного протока.

Видеолапароскопическая операция ушивания перфоративных язв выполнена у 175 паци- 
Огляди літератури, оригінальні дослідження, погляд на проблему

ентов в возрасте от 18 до 80 лет. При диагностической лапароскопии устанавливался диагноз с определением возможности ушивания перфорации с использованием эндовидеохирургической технологии. Ушивание производилось с помощью однорядного шва нерассасывающим материалом с последующим укреплением линии швов прядью большого сальника на ножке. Герметичность швов оценивалась пробой с раздуванием желудка через назогастральный зонд. Осуществлялась тщательная санация брюшной полости с помощью лаважа антисептическими растворами. Операция завершалась дренированием брюшной полости с использованием 2-4 дренажей. При операции ограниченный перитонит обнаружен у 113 (64,6 \%) больных, распространенный перитонит имел место у 62 (35,4 \%) больных. Ушивание производили атравматичным шовным материалом, подбирая размер иглы, соответствующий диаметру перфоративного отверстия. Узлы завязывали экстракорпорально. Трудности ушивания были обусловлены локализацией перфоративного отверстия. Наиболее просто оно осуществлялось при локализации язвы на передней стенке луковицы двенадцатиперстной кишки или желудка. При этом удалось надежно на достаточном расстоянии от краев перфоративного отверстия наложить швы без натяжения. Если имелись сомнения в надежности швов, применяли ряд мер, направленных на их устранение. В частности, использовали биологическую тампонаду перфоративного отверстия сальником. При расположении перфоративного отверстия у малой кривизны наложение эндошвов было затруднено из-за ограниченной подвижности стенок. Если перфоративное отверстие находилось на малой кривизне, от лапароскопического ушивания отказывались (7 случаев конверсий). В послеоперационном периоде больным проводили антибактериальную терапию. Дренажи из брюшной полости извлекали через 12-14 часов, после ультразвукового исследования. В первые сутки после операции все больные не испытывали выраженных болей и могли ходить в пределах хирургического отделения. Осложнений и летальности во время операции и в послеоперационном периоде не отмечено. Средний койко/день - 5.

Видеолапароскопия выполнена у 86 больных с острой кишечной непроходимостью. Спаечная непроходимость выявлена в 69, заворот сигмовидной кишки - в 10, заворот тонкой кишки - В 7 случаях. В экстренном порядке были оперированы 52 (60,5 \%) больных, остальные - после предоперационной подготовки. Среди пациентов со спаечной кишечной непроходимостью у 8 в анамнезе были неоднократные вмешательства на органах брюшной полости. Конверсия осуществлена у 11 (12,8 \%) больных: ввиду массивного спаечного процесса у 5 больных, резкого вздутия петель кишечника у 4, из-за некроза кишки у 2 больных. Противопоказанием для проведения лапароскопии считали интимное сращение органов с париетальной брюшиной, выраженность спаечного процесса, при перфорации и кровотечении из полого органа на фоне острой кишечной непроходимости. Для интраоперационной профилактики спаечной болезни брюшины в конце операции вводили дезагреганты, раствор Реамберина. Послеоперационный период составил от 2 до 12 суток (в среднем 6,8 дня).

Видеолапароскопия выполнена 63 пациентам с сочетанной травмой живота и органов забрюшинного пространства с пневмо- и гемоперитонеумом, а также 57 пострадавшим, у которых возникли возможности оказания помощи эндохирургическими способами при выполнении диагностической видеолапароскопии - как элемент исследования, или вслед за ней. Всем больным при поступлении выполнялась УЗИ или КТ, в зависимости от выявленного количества жидкости, и определялась дальнейшая лечебная тактика. у 35 (29,2 \%) больных после видеолапароскопии не потребовались оперативные вмешательства, так как повреждений внутренних органов не обнаружено, или они были незначительные и не нуждались в хирургической коррекции (повреждения брюшины, сальника и связок, ушибы органов брюшной полости). Эндохирургические операции выполнены 33 (27,5 \%) пациентам. После диагностической видеолапароскопии или в результате конверсии открытые операции выполнены у 52 (43,3 \%) пациентов - это были массивные разрушения печени, селезенки, брыжейки, желудка, тонкой кишки, толстого кишечника и диафрагмы.

Таким образом, видеолапароскопия при сочетанной травме живота позволила визуализировать зону повреждений, выявить наличие гемоперитонеума и оценить его объем, обнаружить прямые или косвенные признаки повреждений внутренних органов, определить тактику лечения, подтвердить или опровергнуть доминирующий характер абдоминальной травмы, выполнить эндохирургическую операцию.

Видеолапароскопия активно применялась для диагностики ранних послеоперационных осложнений. В ближайшем послеоперационном периоде лапароскопия выполнена у 61 больного, с подозрением на перитонит или внутрибрюшное кровотечение. В 7 случаях диагностирован распространенный перитонит, что послужило выполнением экстренной лапаротомии. У 54 боль- 
Огляди літератури, оригінальні дослідження, погляд на проблему

ных при лапароскопии был выявлен местный перитонит, что позволило произвести лапароскопическую санацию и избежать релапаротомии. В 5 случаях при развитии желчного перитонита после холецистэктомии выполнена лапароскопическая диатермокоагуляция ложа желчного пузыря.

Выводы. Видеолапароскопия является высокоэффективным, безопасным, малотравматичным способом хирургического лечения, дает наименьшее количество послеоперационных осложнений, способствует ранней активизации больных, следовательно, является экономически выгодным, так как сокращает сроки пребывания больных в стационаре. Резко сокращается количество напрасных лапаротомий и их осложнений в виде эвентраций, послеоперационных грыж и нагноений ран, что резко увеличивает качество жизни.

\section{ЛИТЕРАТУРА}

1. Возможности применения традиционной лапароскопии и эндовидеохирургических методик в совершенствовании экстренной хирургической помощи / Александров А. И., Феденко В. В., Абдуллаев Э. Г. [и др.] // Эндоскопическая хирургия. - 2001. - № 2. - С.1-2.

2. Жестков К. Г. Эндоскопическая хирургия наиболее распространенных неотложных хирургиче- ских заболеваний / К. Г. Жестков, О.В.Воскресенский, Б. В. Барский // Эндоскопическая хирургия. - 2004. № 2. - C. 53-61.

3. Возможности лапароскопической технологии в ургентной хирургии / Касумьян С. Л., Некрасов А. Ю., Покусаев Б. А. [и др.] // Эндоскопическая хирургия. 2001. - № 2. - C. 31.

\section{EMERGENSY ENDOVIDEOSURGERY WHEN ACUTE DISEASES OF ORGANS OF ABDOMINAL CAVITY}

@U. B. Abdullayev, S. I. Narzulayev, K. R. Tahayev

Samarkand State Medical Institute,

Samarkand Branch of Republican Scientific Centre of Emergency Medical Aid, Republic of Usbekystan

SUMMARY. The basis of research included results of diagnostics and treatment by videoendoscopic interventions of 1812 patients with urgent surgical diseases of abdominal cavity and also the videolaparoscopy was done for patients with diagnostic purpose. During the carried-out researches it was established that the video laparoscopy is highly effective, safe, less traumatic way of surgical treatment. The quantity of the open laparotomies and their complications as eventration, postoperative hernias and suppurations of wounds was reduced.

KEY WORDS: laparoscopy, endovideosurgery , concomitant abdominal trauma 